Témoigner Témoigner. Entre histoire et mémoire

Getuigen Revue pluridisciplinaire de la Fondation Auschwitz

$124 \mid 2017$

La musique dans les camps

\title{
De deportatie van vrouwen uit bezet Frankrijk
}

Nieuwe perspectieven

Les femmes déportées de France par mesure de répression:

nouvelles perspectives

Pierre-Emmanuel Dufayel

Traducteur : Gorik de Henau

\section{CpenEdition}

Journals

Édition électronique

URL : https://journals.openedition.org/temoigner/5797

DOI : 10.4000/temoigner.5797

ISSN : 2506-6390

Éditeur :

Éditions du Centre d'études et de documentation Mémoire d'Auschwitz, Éditions Kimé

Édition imprimée

Date de publication : 2 avril 2017

Pagination : 143-153

ISBN : 978-2-930953-00-7

ISSN : 2031-4183

Référence électronique

Pierre-Emmanuel Dufayel, «De deportatie van vrouwen uit bezet Frankrijk», Témoigner. Entre histoire et mémoire [Online], 124 | 2017, Online op 30 novembre 2021, geraadpleegd op 01 décembre 2021. URL: http://journals.openedition.org/temoigner/5797 ; DOl: https://doi.org/10.4000/temoigner.5797 


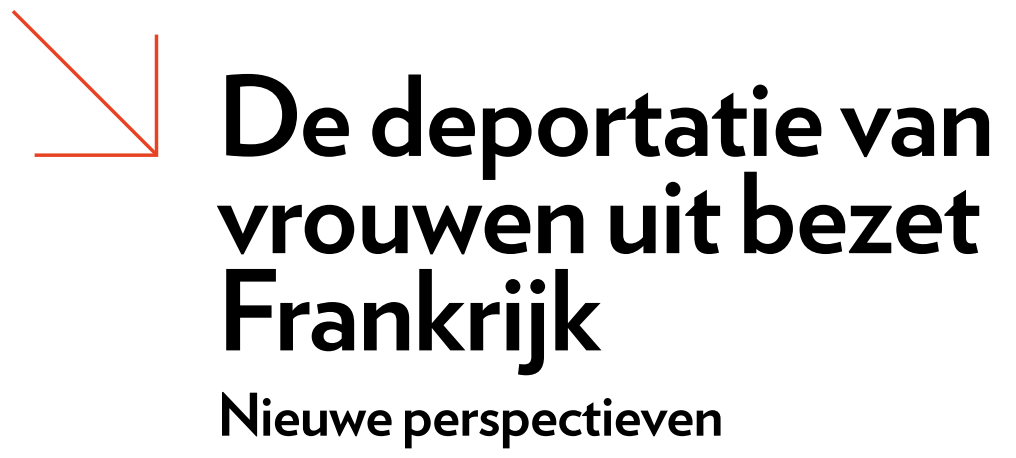

\footnotetext{
$\rightarrow$ Pierre-Emmanuel Dufayel

Université de Caen BasseNormandie Vertaling uit het Frans: Gorik de Henau
}

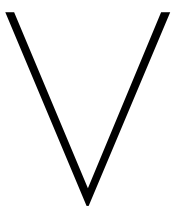

oor de vrouwen die tijdens de bezetting in Frankrijk woonden, was deportatie zowat het equivalent van de plicht om het vaderland te dienen. Het lijden van duizenden vrouwen symboliseert op krachtige wijze de offers die de tweede sekse bracht voor de verdediging van het land, en ook hoe zij bijdroegen tot de strijd van het ondergrondse verzetsleger. De overgrote meerderheid van de vrouwelijke slachtoffers van het bestraffingsbeleid - waarmee de bezetter de orde trachtte te handhaven - werd gedeporteerd.

Tot midden de jaren negentig, toen de Fondation pour la Mémoire de la Déportation met een herdenkingsboek het deportatieproces weer up-to-date bracht, bleef de wetenschappelijke vooruitgang evenwel beperkt tot het bestuderen van het dagelijks leven van vrouwelijke gedeporteerden in de concentratiekampen. Bijna een halve eeuw lang deden de gedeporteerden zelf het grootste deel van het werk. Moeten we hier nog herinneren aan het pionierswerk van Germaine Tillion, die meteen na haar repatriëring naar Zweden in april 1945 begon aan een systematische inventaris van de beschikbare informatie? Ook vandaag nog blijft dit het verplichte vertrekpunt voor alle opzoekingen naar Franse gedeporteerden. In het kielzog van haar meesterlijke boek Ravensbrück spitste het onderzoek zich tientallen jaren toe op de werking en organisatie van het grootste vrouwenconcentratiekamp in het Reich. Daar werden meer dan 100000 vrouwen en meer dan 20000 mannen geïnterneerd, waardoor het vanzelf de referentieplek werd voor de nagedachtenis van de vrouwelijke slachtoffers van nazi-Duitsland. Meer dan zeventig jaar na de terugkeer van de laatste gedeporteerden wordt de karige bibliografie op dat vlak nog altijd gedomineerd door publicaties over de werking van het kamp Ravensbrück. Recentelijk nog publiceerde 
Bernhard Strebel met het monumentale Das KZ Ravensbrück een even volledige als nauwgezette studie over het kamp.

De archieven van het kamp werden voor de bevrijding vernietigd, waardoor de historiografen er in de loop der jaren van overtuigd raakten dat het een geschiedenis zonder archieven betrof. Zo ontstond het idee dat het een haast onmogelijke of minstens onpraktische opdracht was om een dergelijke geschiedenis te schrijven op basis van geschreven bronnen. Maar uit recente studies blijkt juist dat er hee wat informatie voorhanden is en dat het mogelijk is daarmee het verhaal van de vrouwelijke deportatie neer te schrijven. Dat zullen we trachten aan te tonen in
een eerste punt.

Dankzij nieuwe bronnen kon het onderzoeksveld aanzienlijk verbreed worden en werden nieuwe vragen gesteld. Als gevolg van publicaties (bijvoorbeeld van Thomas Fontaine en Gaël Eismann) die nieuw licht werpen op het onderdrukkings- en ordehandhavingsbeleid in bezet Frankrijk is de kwestie van het vrouwelijke deportatieproces op de voorgrond getreden. We kunnen nu ook de sociaal-politieke omstandigheden en de diverse trajecten van deze vrouwen analyseren, en op die manier een preciezere en complexere definitie formuleren van de deportatie.

\section{VROUWELIJKE DEPORTATIE, EEN GESCHIEDENIS ZONDER ARCHIEVEN?}

Het idee dat de geschiedenis van de vrouwelijke deportatie zonder archieven moet worden geschreven, dateert van net na de oorlog. Om te begrijpen hoe het ingang vond in die overgangsperiode moeten we terugkeren naar de rol die de overlevenden speelden in de historiografie van de vrouwelijke deportatie, in het bijzonder dan Germaine Tillion. Voortbouwend op haar opleiding als etnoloog en haar ervaring met veldwerk - in Algerije deed Tillion onderzoek naar Algerijnse Berberstammen, bij wie ze jarenlang verbleef - en met behulp van haar scherpe observatievermogen analyseerde ze al in de eerste maanden van haar deportatie hoe het kamp functioneerde. Via gevangenen die in de verschillende diensten waren tewerkgesteld trachtteze informatie teverzmelenoverantallen, demanschappen tewerk in het kamp en de econonischeldzame luciditeit, waardoor ze toen al belangrijke aspecten van het concentratiekampsysteem begreep. Aangezien ze tot het laatst in Ravensbrück bleef, was ze zoals veel gevangenen getuige van de vernietiging van de kamparchieven. Toen de nederlaag onvermijdelijk bleek, vernietigden de nazi's tweeënhalve week lang de documenten aangaande de kampadministratie, om te beginnen die betreffende de politieke sectie, die zonder enige twijfel de meeste informatie bevatte over de gevangenen. Een aanzienlijk aantal documenten dat van cruciaal belang was voor de geschiedschrijving van de vrouwelijke deportatie ging verloren.

Meteen na haar bevrijding begon Germaine Tillion, die zich toen in Zweden bevond, met het ondervragen van overlevenden, ze verzamelde zovel mogelijk bevond, met he namen en registratienummins, en stelde een eerste lijst op. De overlevende gede-

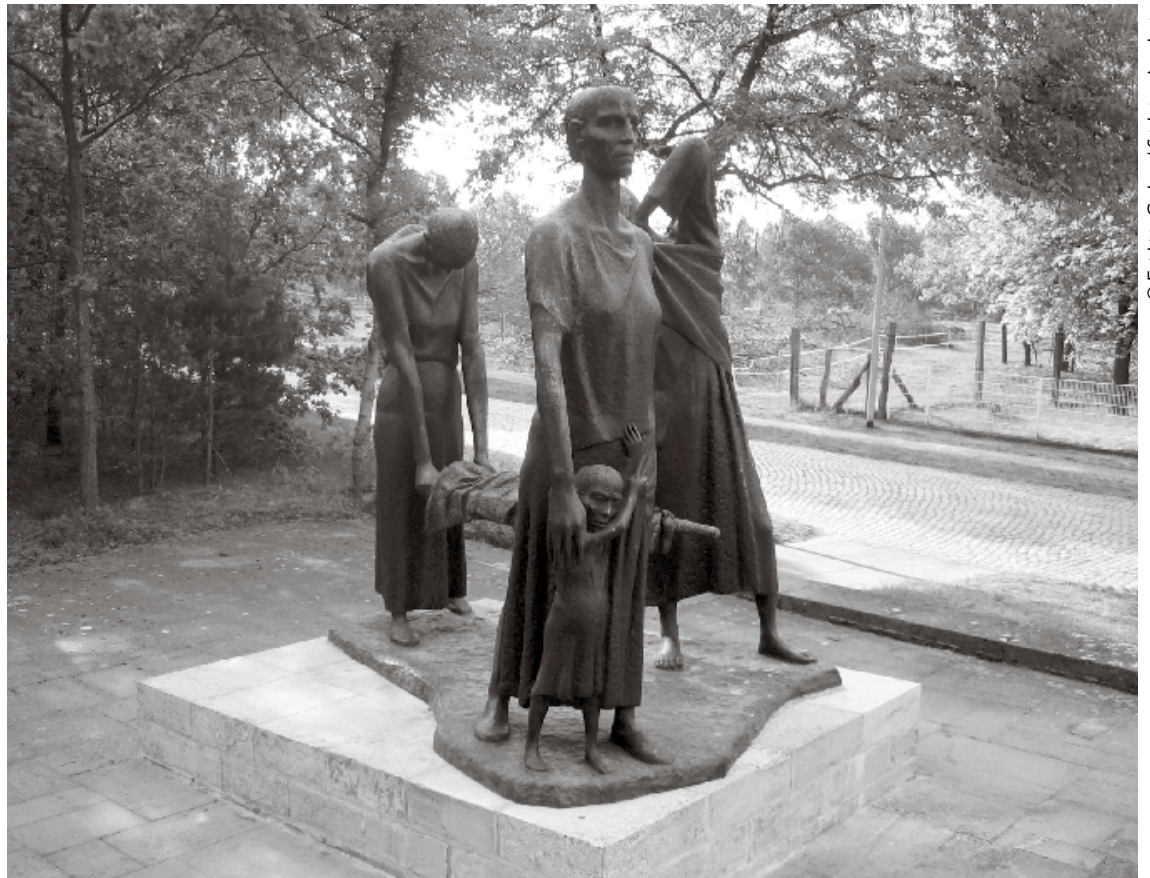

-Tragende van Wil

de werking van het kamp al hadden bestudeerd, moesten zich vanaf dat ogenblik koste wat het kost de namen van de slachtoffers herinneren. In de eerste weken na de bevrijding kwam bij Germaine Tillion en haar kameraden het idee op dat ze de geschiedenis van de vrouwelijke deportatie hoogstwaarschijnlijk zonder archieven moesten schrijven. Die vaststelling drukte Germaine Tillion een paar jaar later zo uit: 'Toen de deuren van het laatste Duitse concentratiekamp opengingen, nam die "andere wereld" geen fysieke ruimte meer in, om te gan behoren tot de nam die "ancer we gestverschijningen van " "historische en naakt als de doden die er deel van uitmaakten. (Tillion 1954, 38) Na de oorlog zette ze haar onderzoek naar deze geschiedenis 'zonder bagage' voort. Eerst maakte ze deel uit van de Commission des Déportés et Internés Politiques et Raciaux, en toen in juni 1951 binnen het historische comité voor de Tweede Wereldoorlog de Commission d'Histoire de la Déportation werd opgericht, werd ze daar ondervoorzitter van.

Tot eind jaren zeventig werd de geschiedenis dus geschreven door de gedeporteerden zelf, hoofdzakelijk op basis van hun getuigenissen en mondeling onderzoek. Het was een uitgebreide verzameling getuigenissen die op uiterst methodische wijze tot stand kwam en zeer betrouwbare gegevens bevatte over het antal slachtoffers en de chror Tillion de Tillion en een reeks kameraden een groot aantal getuigenissen, opgesplitst per kamp,
transport en thema. Ze slaagden er naar best vermogen in via de herinneringen van 


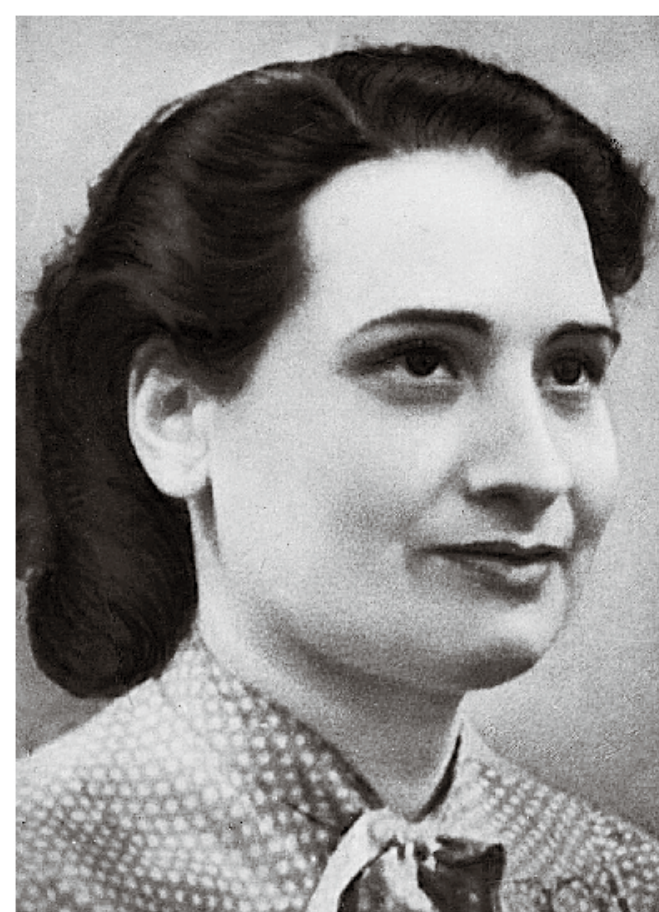

de overlevenden de leemte op te vullen die was ontstaan door het vernietigen van de archieven van het kamp Ravensbrück. In de periode dat de opzoekingen naar de deportatie het meest intens waren en de voormalige gedeporteerden ertoe werden aangezet hun verhaal neer te schrijven, werd vastgehouden aan het idee van een geschiedenis zonder archieven, want men wantrouwde (Duitse) documenten. Germaine Tillion drukte het zo uit in het besluit van een onderzoek dat ze deed naar de bijdrage van getuigenissen aan de studie van de deportatie: 'Het heftigste relaa boordevol foutenbenadertwaaschijnlijk nogdichter de warheid en is hoe danook boordevol fouten benadert waarschijnlijk nog dichter de waa

Je kunt je dus met recht en reden vragen stellen over het misbruik van en/of het niet-gebruik-maken-van documentatiemateriaal dat nochtans binnen handbereik is. Dat een en ander al die jaren toch werd volgehouden is grotendeels te wijten aan polarisatie en het feit dat het onderzoek zich toespitste op het centrale Ravensbrück-kamp. Een groot deel van de uit Frankrijk gedeporteerde vrouwen mocht dan door het kamp passeren, de overgrote meerderheid van hen vertrok naar andere deportatieplaatsen. In tegenstelling tot de globale visie die soms nog aanhoudt, was Ravensbrück niet de enige bestemming van de gedeporteerden. De facto bleef slechts een kleine minderheid er voor de hele duur van de deportatie. lijke deportatie uit Frankrijk kan worden geschreven. We lijke deportatie uit Frankrijk kan worden geschreven. We moeten meteen meegeven dat er archieven van het kamp Ravensbrückbewaard zijn gebleven. Onuitgegeven bronnen openen nieuwe perspectieven: transportlijsten, individuele gevangenenfiches, lijsten van overplaatsingen, vragenlijsten die bij intrede werden afgenomen. Dankzij recent onderzoek kon trouwens de rol van de militaire administratie worden belicht, waardoor een beter zicht ontstond op de archieven van de verschillende diensten, meer bepaald de magistratuur en de militaire rechtbanken.

Voor de studie van de vrouwelijke deportatie beschikken (a) menten van het bestrefngelementen van het bestraffingsapparaat, bijvoorbeeld gevangenissen en interneringskampen, bestaat opnieuw heel wat documentatie. Specifiek wat viouwen betreft, beschikken we over de archieven van het kamp in Romainville, het belangrijkste interneringskamp voor vrouwen alvorens ze naar de concentratiekampen vertrokken; vanaf 1943 was het een essentieel onderdeel van de organisatie van de transporten naar Ravensbrück. Het register werd volledig bewaard en op basis daarvan kunnen de meeste vertrektijden van vrouwen worden gerecontrueerd. We vermeldenden van vrouwen wo den ger de gevangenen en de verschillende overplaatsingen.
Het blijkt ook noodzakelijk de repatriëringsarchieven te raadplegen. Daar wordt nog veel te weinig gebruik van gemaakt, hoewel ze een groot aantal documenten bevatten over de periode van de bevrijding tot aan de terugkeer van de gedeporteerden naar Frankrijk (een tijdspanne van soms meerdere maanden). We vinden er informatie over de lotgevallen van de gedeporteerden en de bevrijdingsacties van het internationale en het Zweedse Rode Kruis tijdens de laatste oorlogsweken. Ze bevatten veel fotomateriaal omtrent de in Zweden vervaardigde pasjes.

Tot slot moeten we het hebben over de naoorlogse bronnen, bijvoorbeeld de , bijvoorbeeld de individuele dossiers die slachtoffers en hun families samenstelden om een bewijsstuk of een vermelding te verkrijgen. ${ }^{1}$ Dankzij deze archieven, die nu grotendeels toegankelijk zijn, kan nieuw onderzoek worden verricht naar gedeporteerden en de deportatie.

EVOLUTIE VAN HET BESTRAFFINGS- EN DEPORTATIEBELEID IN BEZET FRANKRIJK

Tussen 1940 en 1944 werden ongeveer 6700 vrouwen gedeporteerd vanuit de bezette gebieden in Frankrijk en bijna 2200 vanuit de Elzas en de Moezelstreek, beide geannexeerd. In wat volot zullen we het vooral hebben over de deportatie vanuit de bezette gebieden. De bestrafing en deportatie vanuit de geannexerde vanuit cexeerde Elzas-Moezelstreek hecifieke werken, meer bepald de bezetting en al die tijd kende de deportatie geen eenduidig verloop, maar nam verschillende vormen aan. Vrouwelijke deportatie verliep eerst in het raam van de juridische strafmaatregelen die werden toegepast door de Duitse militaire administratie (de MBF [Militärbefehlshaber in Frankreich] en de MBB [Militärbefehlshaber in Belgien und Nord Frankreich]). De eerste uit Frankrijk gedeporteerde vrouwen waren door Duitse militaire rechtbanken veroordeeld en werden naar gevangenissen in het Reich gebracht om daar hun straf uit te zitten. Françoise de Hauteclocque bijvoorbeeld, een van de eerste vrouwen die uit Frankrijk werden gedeporteerd, werd op 4 augustus 1940 opgepalt in Ste-Suzanne-par-Prétôt in het departement Manche; de Feldgendarmerie arresteerde haar voor wapenbezit en de weigering een bevel op te volgen.'s Anderendaags werd ze berecht door een krijgsraad van de $12^{\mathrm{e}}$ infanteriedivisie; ze werd veroordeeld tot zes maand opsluiting en op 6 augustus gedeporteerd naar de gevangenis van Keulen, waar ze na haar straf werd vrijgelaten. Vanaf 1941 werd de rechtspraak steeds strenger als reactie op het almaar beter georganiseerde verzet. In de volledige bezette gebieden werden meer dan 150 vrouwen veroordeeld en vervolgens gedeporteerd; minstens 110 van hen werden vanaf 1941 naar Duitsland overgebracht. Voor het eerst werden ook vrouwen tot de doodstraf veroordeeld. Zo werd Kate Bonnefous op 13 november 1940 aangehouden voor het helpen van ontsnapte krijosgevangenen en vervolgens op 7 maart 1941 door de militaire rechtbank van Grand Paris ter dood veroordeeld. Op 7 juli werd ze ne militaire recher Triergenenissen. Meestal ook in het geval van Kate Bonnefous, werd de doodstraf omgezet in (1) Beward in Caen bij
de Division des Archives
des Vicitimes des Conflits
Pats Contemperains, Service

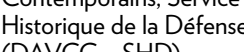


levenslange opsluiting, want de ter dood veroordeelde vrouwen mochten in Frankrijk niet worden gefusilleerd. Toch werden bepaalde vrouwelijke verzetsstrijders uit communistische organisaties en partizanengroepen niet gespaard. Françoise Bloch-Serazin bijvoorbeeld, die van in de eerste oorlogsmaanden actief was binnen de Parijse groep FTP, werd op 15 mei 1942 aangehouden toen de speciale brigade van de Franse politie in haar eigen appartement een valstrik opzette. Op 30 september 1942 werd ze ter dood veroordeeld door de Duitse militaire rechtbank in Grand Paris, op 16 november 1942 gedeporteerd naar Lübeck en vervolgens Hamburg (1) waar haar straf uiteindelijk op 12 februari 1943 werd uitgevoerd. Olga Bancic, een Joods-Roemeense migrant en verzetsstrijder uit de Missak Manouchian-groep, werd ook naar Duitsland overgebracht, nadat ze net als haar kameraden van de 'Affich Rouge' ter dood was veroordeeld. Op 10 mei 1944 werd ze onthoofd in Stuttgart. Ook Syma Schloss, een arbeidster van Poolse afkomst, werd met de valbijl geëxecuteerd in Keulen, nadat ze op 24 april 1942 in Parijs ter dood was veroordeeld wegens het drukken en verspreiden van vlugschriften binnen het communistische verzet.

In december 1941 vaardigde maarschalk Keitel, de opperbevelhebber van de Wehrmacht, de zogenoemde Nacht und Nebel-verordening (NN) uit. Voortaan zouden in Frankrijk alleen nog de verzetsstrijders worden berecht die binnen de week nahun arrestatie ter dood konden worden veroordeelden terechtgesteld Deandere nahnere verdachten werden in het grootste geheim naar Duitsland overgebracht om daar door een burgerlijke of militaire rechtbank te worden berecht. Door die verdachten in 'de nacht en de mist' te laten verdwijnen, werd getracht het afschrikkende karakte van de maatregel te versterken. Tussen eind 1941 en lente 1944 waren in Frankrijk bijna 1000 vrouwen het slachtoffer van de NN-procedure. ${ }^{2}$ Léonie Kerforn werd op 2 april 1942 gearresteerd voor het verspreiden van foto's met de beeltenis van generaal De Gaulle. Een maand later werd ze in het grootste geheim naar Duitsland overgebracht, waar ze door de buitengewone rechtbank in Keulen tot vier jaar opsluiting werd veroordeeld. De Duitse politie gebruikte vanaf voorjaar 1943 de NN-procedure om in het seniep gedetineerden via de gevangenis over te brengen nar de concentratiekan

Injuni 1942 nam de Sipo-SD de politietaken over van de militaire administratie in Frankrijk en riep ze een nieuw bestraffingsapparaat in het leven, waarvan deportatie naar de concentratiekampen geleidelijk de hoeksteen werd. Begin 1943 eigende ze zich op basis van het Schutzhaft-principe (preventieve hechtenis) officieel het recht toe om verdachten zonder vorm van proces op te sluiten. Vanaf dat ogenblik werd de overgrote meerderheid van de gedeporteerde vrouwen, na verschillende maanden detentie in Franse gevangenissen, verzameld in Compiègne en daarna in het fort van Romainville, dat vanaf 1944 voor Franse vrouwen de wachtkamer van de deportatie werd. Het eerste directe transport van vrouwen dateert van 23 januari 1943. Het ging richting Auschwitz en omvatte 230 vrouwen van wie het merendeel bekende communistische activisten warn, onder anderen Danielle Casanova, Chende com Delboen Marie-Clive Vaillokken gebieden ongeveer 4800 vrouwen gedeporteerd, wat neerkomt op twee derde van de vrouwen die uit Frankrijk in het raam van het bestraffingsbeleid werden gedeporteerd. Op 31 januari kwam met 959 vrouwen het grootste transport tijdens de bezetting tot stand. In het voorjaar van 1944 organiseerden de Duitsers transporten met 50 tot 60 gevangenen naar het kamp Neue Bremm in Saarbrücken, vanwaar grotere transporten richting Ravensbrück vertrokken. Maar de deportatie van de door militaire rechtbanken veroordeelde vrouwen ging voort. Meer dan honderd werden er op die manier van Frankrijk naar Duitse gevangenissen overgebracht. werden er op die mani In het najaar van 1944, na de intrekking van de NN-verordering, werd de overgrote meerderheid van de vrouwelijke gevangenen die zich nog in Duitse gevangenissen
bevonden naar Ravensbrück overgebracht.

\section{PROFIEL VAN DE GEDEPORTEERDE VROUWEN}

Als we kijken naar het sociaal-politieke profiel van de gedeporteerde vrouwen, staan we voor een dubbele uitdaging: ten eerste weten wie met de procedure werd bestraft en wie de Duitsers besloten te deporteren, ten tweede de vrouwelijke slachtoffers van dat bestraffinossbeleid opnieuw een identiteit bezorgen. De Division des Archives des Victimes des Conflits Contemporains (DAVCC) beschikt over dosiers ( aangaande de aanvragen van het statuut van politiek gedeporteerde en verzetsstrijder. Van de vrouwen over wie na de oorlog geen dossier was aangelegd, werden de gegevens onderzocht met het oog op hun arrestatiegrond en voorafgaande activi-
teit; die informatie werd gevonden voor 5832 van de 6672 uit Frans bezet gebied gedeporteerde vrouwen, dat wil zeggen voor 88 procent.

De overgrote meerderheid van de gedeporteerde vrouwen streed wel degelijk tegen de bezetter en/of het Vichyregime, maar op basis van de bestudeerde bronnen kunnen we de term 'verzetsstrijder' nu aanzienlijk bijstellen. Vooreerst blijkt dat ongeveer 64 procent van de gedeporteerden lid was van een verzetsorganisatie. ${ }^{3}$ Bijna de helft maakte deel uit van een netwerk, 20 procent was actief binnen een beweging en ongeveer 30 procent was lid van een organisatie die verbonden was met het communistische verzet (bijvoorbeeld Front National of FTPF/Francsmet het communistische verzet (bijvoorbeeld Front National of FTPF/Francsnen die organisaties blijkt hoe gevarieerd hun acties wel waren en ook het domein waarin ze zich specialiseerden. Naast opdrachten op het vlak van sociale diensten (2 procent), het opvangen van valschermspringers (2 procent) en het voorbereiden van sabotagedaden waren de gedeporteerde vrouwen ook actief bij het naar buiten smokkelen van voortvluchtige gevangenen, piloten die waren neergeschoten boven vijandelijk terrein en spionnen op weg naar Engeland (7 procent). Bijna 15 procent van de gedeporteerden in een verzetsorganisatie vervulde taken in verband met informatieverogring (van het ontvreemden van officiële documenten over het onderscon van brieven voor de Kommandantur to het gadeslan van Duitse onderscheppen van brieven voor de Kommandantur tot het gadeslaan van Duitse troepenbewegingen), terwijl meer can (verdeling druk, redactie)
(3) De aangehaalde statistieken
konden worden opgesteld na het openen van de statuutdossiers 


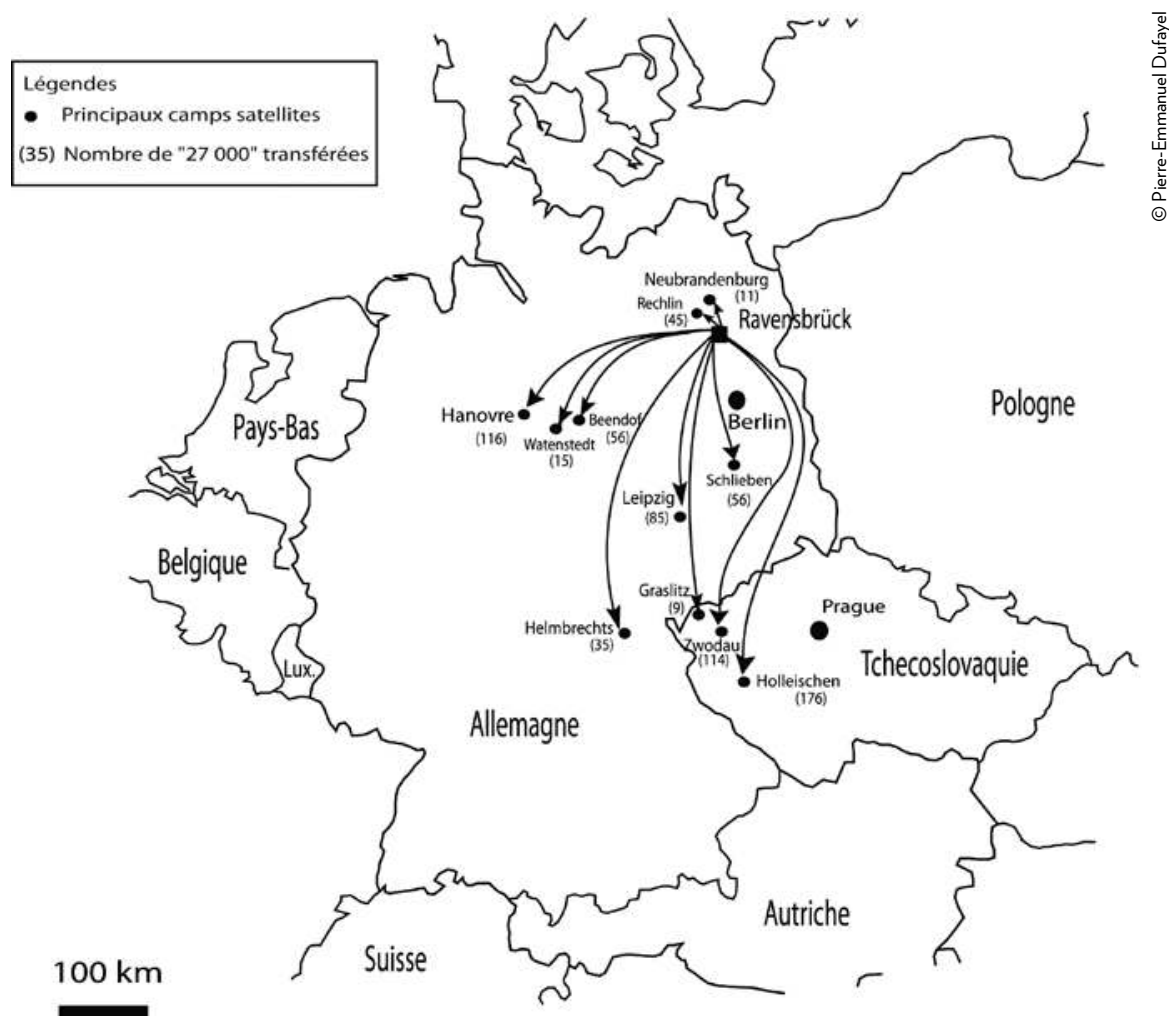

ken uit het nieuwe onderzoeksmateriaal is de noodzaak om de blik af te wenden van het centrale Ravensbrück-kamp. Uit de trajectanalyse blijkt de geografische verscheidenheid van de deportatieplaatsen, of het nu gaat om de talrijke satellietkampen en a heid kampen n a beid Franse vrouwen weden opgeston. Zo werd Jeanne Bonneaux, op 15 maart 1942 in Parijs opgepakt voor verzetsactiviteiten, naar acht verschillende gevangenissen overgebracht voor ze op 21 november 1944 in Ravensbrück terechtkwam. Sommige gedeporteerden, bijvoorbeeld Marie-Louise Le Bozec, werden naar wel twaalf verschillende plaatsen overgebracht. Bijna 1900 vrouwen deden op hun traject een gevangenis aan, terwijl minstens 900 niet in een concentratiekamp belandden. ${ }^{4} \mathrm{Uit}$ een studie van die honderden trajecten blijkt duidelijk het veelsoortige en caleidoscopische karakter van de deportatie-ervaring. Willen we de omvang van die bestraffing in kaart brengen, moeten we het dus ook hebben over de gevangenissen in Jauer, Cottbus, Gotteszel, Aichach en Flüssbach.

In de loop van 1943 werd Ravensbrück trouwens een enorme draaischijf voor het verspreiden van vrouwen uit heel Europa over de Duitse oorlogseconomie. Meer dan twee derde van de uit Frankrijk gedeporteerde vrouwen werd vanuit dat kamp overgebracht naar wapenfabrieken van het Balticum tot Sudetenland. Een mooi voorbeeld daarvan is de verspreiding van de vrouwen uit het transport dat op 31 januari uit Compiègne vertrok en op 2 februari in Ravensbrück aankwam. Meer dan zeven op de tien vrouwen werden overgeplaatst naar een arbeidsploeg. Vanaf april werden ongeveer 300 van hen eerst naar Holleischen en Zwodau in Sudetenland overgebracht, vervolgens vertrokken in juli meer dan honderd vrouwen naar het Limmer-kamp in Hannover en tot slot gingen er twee weken later bijna evenveel van Ravensbrïck nar Leipzig. Er wordt geschat dat bij de deportatie van Franse vouw Franse vat bijvoorbeeld wwar van 1944 een deel naar Frankrijk werd gerepatrieerd om te bevallen. Er waren ook vrouwelijke gevangenen die vervroegd vrijkwamen, buiten de standaardprocedure om, zoals Geneviève de Gaulle.

Via de studie van het lot van de gedeporteerden kunnen we tot slot een precieze balans opmaken van het bestraffingsbeleid. Het onderzoek leert ons dat $1533 \mathrm{vrou}-$ wen verdwenen of overleden tijdens hun deportatie, dat wil zeggen 24 procent van de uit bezet Frankrijk weggevoerde vrouwen. De lotsbestemming van 184 vrouwen blijft tot op vandaag onbekend. Meer dan de helft van de vrouwen overleed tussen 1 februarien 30 april 1945, tijdens een periode waarinde uitroeiing van de zwaksten werd georganiseerd in het centrale Ravensbrück-kamp. In zes op de tien geval

was Ravensbrück voor de gedeporteerde vrouwen de plaats van overlijden.

Door de problematiekvan de vrouwelijke deportatie opnieuw te bekijken kunnen we een gefragmenteerde geschiedenis weer samenstellen en verzet, politieke onderdrukking en het concentratiekampsysteem vanuit eenzelfde standpunt beschouwen. Op die manier wordt een preciezer en tegelijk vollediger visie mogelijk. We kunnen wat meer afstand nemen van een eenvormig totaalschema waarin beide geslachten op een hoopje worden gegooid en verschillen genegeerd. We kunnen licht werpen op het specifieke karakter van de vrouwelijke deportatie, die ook vandaag nog een schemerzone blijft in de vrouwengeschiedenis. I
BIBLIOGRAFIE - Pierre-Emmanuel Dufayel,
Un convoi de femmes, Parijs - Gaël Eismann, Hôtel Majestic. Ordre et sécurité en France occupée (1940-1944), Parijs - Fondation pour la Mémoire de
la Déportation, Livre-Mémorial par deposurese de France arrêtés dans certains cas part mesure de
persécution. 1940-1945, Parijs: Tirésias, 2004

- Thomas Fontaine, Les oubliés deos.

- Catherine Lacour-Astol, Le

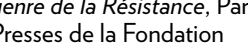
nationale de sciences politiques,

- Bernhard Strebel, Das KZ Ravensbrück. Geschichte Paderborn: Ferdinara
Schöningh, 2003.

- Germaine Tillion, Ravensbrück -... 'Réflexion sur létude de la déportation', in Reverue d'Histoire de la Seconde Guerre mondiale,
$4(15)$, juli-september $1954,3-38$ 